\title{
Diversidade, Tensões e Convergências: prestação de contas de um mandato e do $X$ Congresso Paulista de Saúde Pública
}

\section{Diversity, Tensions and Convergences: results of a term of office and of the $10^{\text {th }}$ São Paulo's Congress of Public Health}

\author{
Marco Akerman \\ Presidente da Associação Paulista de Saúde Pública (APSP), biênio \\ 2006-2007. Professor Titular de Saúde Coletiva da FMABC (licencia- \\ do); Consultor de Saúde e Desenvolvimento Local da Organização \\ Pan-Americana da Saúde (OPAS). \\ E-mail: akermanmळterra.com.br
}

\section{Diversidade, Tensões e Convergências de um Mandato}

Marco Akerman, Mara Helena de Andréa Gomes, Rita de Cássia Seixas Sampaio Araújo, Olinda do Carmo Luiz, Luiz Antonio Dias Quitério, Luana Carandina trouxeram ao mandato 2006-2007 da Associação Paulista de Saúde Pública (APSP) diversidade de experiências e de idéias, geradoras de tensões criativas que nos convergiram para dar seqüência e conseqüência às tradições, compromissos, conquistas e atividades que a APSP vem estabelecendo ao longo dos seus 35 anos de vida.

Com essa necessária convergência alcançamos algumas realizações: (1) revitalização do consagrado "Bartepapo"; o (2) reconhecimento e valorização da nossa memória histórica com a compilação de documentos e fotos num bem elaborado CD para celebração dos 35 anos da APSP; a (3) consolidação do apoio ao nosso empreendimento comum, com a Faculdade de Saúde Pública da Universidade de São Paulo (FSP/USP), a revista "Saúde e Sociedade", e o seu devido reconhecimento cientifico através da inclusão na base de indexação SCIELO, ocorrido em 2007; a (4) continuidade da nossa presença marcante e efetiva no Conselho Estadual de Saúde, como um dos representantes das entidades de profissionais de saúde; o (5) aperfeiçoamento da nossa gestão administrativa e financeira permitindo maior otimização da nossa capacidade operacional no uso da nossa sede; o (6) apoio a nossa descentralização através dos Núcleos Regionais, com destaque para o reaquecimento do Núcleo de São José dos Campos/Vale do Paraíba; e por último, mas não de somenos importância, a (7) bem sucedida realização do X Congresso Paulista de Saúde Pública, prestigiada por 1.340 participantes e que propiciou um saldo importante de recursos financeiros para o próximo biênio. 


\section{Diversidade, Tensões e Convergências de um Congresso}

"Diversidade, tensões e convergências" não só constituíram o perfil do mandato, mas também, a temática de reflexão do Sistema Único de Saúde (SUS) no X Congresso Paulista de Saúde Pública, promovido e organizado pela Associação Paulista de Saúde Pública e pela Faculdade de Medicina da Universidade Estadual de São Paulo (UNESP), Botucatu, que se realizou entre 27 e 31 de outubro em São Pedro - SP.

Ao saudar a consolidação do SUS como política pública de Estado, o X Congresso Paulista de Saúde Pública se propôs a explicitar as múltiplas e necessárias diferenças que existem nas agendas políticas e intelectuais do sistema de saúde brasileiro; indicou os pontos de tensão entre elas, e aprofundou-os conceitualmente, apontando possíveis caminhos de convergência.

A programação científica se ancorou em três eixos principais: (1) Políticas de atenção à saúde: avanços e impasses; (2) Saúde, Sociedade e Sistema Único de Saúde: o imperativo dos sujeitos; (3) Organização das ações de atenção à saúde: modelos e práticas e que serviram de mote para a reflexão sobres diversidade, tensões e convergências no SUS.

A Comissão Cientifica do X Congresso, coordenada por Elen Rose Lodeiro Castanheira ${ }^{1}$ recebeu a inscrição de 1.044 trabalhos científicos avaliados por 106 revisores, e que selecionaram 962 trabalhos para participarem do Congresso.

1.350 participantes intercambiaram idéia e reflexões num conjunto de atividades, que mobilizou 176 convidados; um Seminário das Escolas Técnicas do SUS com 200 participantes, quatro Oficinas de Trabalho e quatro Cursos Pré-Congresso, 53 salas de discussão temáticas, 20 painéis, três mesas de debates e quatro conferências (incluindo a de Abertura, que contou com a presença do Professor Sozinho Francisco Matsinhe, do Departamento de Línguas Africanas, da Universidade da África do Sul, Pretória). Cumpre assinalar a sessão de homenagem ao sanitarista Kurt Klotzel que emprestou seu nome para os prêmios de melhores trabalhos do X Congresso.

Em termos absolutos, as três primeiras "categorias profissionais" representadas foram os enfermeiros com 202 representantes ("geral" - 87; "sanitarista" - 45; “do Programa de Saúde da Família (PSF)" - 32; "professor de enfermagem" - 21; "enfermeiro do trabalho" - 3; "outros enfermeiros" - 14) seguida pelos médicos com 123 profissionais ("sanitarista" - 54; "clinico geral" - 18; "pediatra” - 8; “outros médicos" - 13; "ginecologista/obstetra" - 7; "geral e comunitário" - 5; "do PSF - 5; "médico do trabalho - 5; "cirurgião - 5; "psiquiatra" - 3; e os "alunos de graduação" com 74 pessoas. E curiosamente: um cantor, um palhaço; um forneiro de porcelana; um engastador de jóias, um zoólogo; um vendedor de comercio varejista, um arquiteto paisagista, um abatedor, um pugilista, um vinagreiro, um acabador de embalagens, uma babá, um astrônomo, um engenheiro aeronáutico e um comerciante atacadista.

Quando se considera a categoria "tipo de inscrição" os alunos de graduação estão em maioria com 208 participantes, seguidos pelos alunos de pós com 186. Essa categoria "tipo de inscrição" talvez seja o melhor medidor de inscritos ao totalizar 917 inscrições pagas (329 não sócios da APSP, 157 sócios, 208 alunos de graduação, 186 de pós-graduação e 37 não informados).

206 pessoas vieram da cidade de São Paulo, 129 de Botucatu, 55 do ABC Paulista (26 de Santo André), 43 de Campinas, 33 de Ribeirão Preto, etc. E 79 congressistas de outros estados (20 de Minas Gerais, 15 do Rio de Janeiro, 12 do Paraná, 7 de Mato Grosso do Sul, 7 do Ceará, 7 de Brasília-Distrito Federal, 4 de Pernambuco, 2 de Santa Catarina, 1 de Goiás, 1 da Paraíba, 1 do Pará, 1 do Amazonas, 1 de Rondônia).

A UNESP de Botucatu aparece no topo da categoria "instituição" com 133 representantes, seguida pela Prefeitura do Município de São Paulo com 59, Universidade Estadual de Campinas (UNICAMP) com 34, FSP/USP, Faculdade de Medicina da USP com 33, Instituto de Saúde/Secretaria de Estado da Saúde de São Paulo com 30, Faculdade de Medicina do ABC com 23, Universidade Federal de São Paulo (UNIFESP) com 22, Escola de Enfermagem de Ribeirão Preto/USP com 18, Agência Nacional de Saúde (ANS) com 16, Universidade Católica de Santo (UNISANTOS) com 14, Secretaria Municipal da Saúde de Botucatu com 13, Pontifícia Universidade Católica (PUC) de Sorocaba com 13, Universidade do Sagrado Coração com 12, Universidade Federal de São Carlos com 11, Faculdade de Medicina de Marília (FAMEMA) com 1o, Faculdade de Ciências Médicas da Santa Casa de São Paulo com 10, Escola de 
Enfermagem da USP com 1o, Centro Universitário São Camilo com 10, Prefeitura do Município de Campinas com 10, etc.

O Congresso foi avaliado pelos participantes a partir de uma amostra de 104 respondentes (70\% de mulheres, $28 \%$ com menos de 30 anos, $81 \%$ residentes do estado de São Paulo) indicando $65 \%$ de ótimos e bons, $22 \%$ de regulares e $13 \%$ de ruins, considerando de forma agregada os quesitos das categorias "organização" (secretaria com a melhor avaliação e pontualidade com a pior avaliação) e "serviços" (programação cultural teve a melhor avaliação e translado a pior avaliação).

\section{Diversidade, Tensões e Convergências em uma Atividade Pré-Congresso}

Pela dimensão (20o participantes) e pela inovação de sua inserção em um Congresso de Saúde Publica (formação técnica no SUS) vale à pena comentar uma das atividades Pré-Congresso, o Seminário de Escolas Técnicas do SUS, para o qual o X Congresso "abriu suas portas".

Abrem-se portas de varias maneiras. Por gentileza, para se dar passagem a alguém. Ou com sua própria chave, quando se chega a um lugar de sua propriedade; ou mesmo, arrombando-as, rompendo-as para se entrar em um lugar que não lhe pertence ou que não lhe permitam estar.

Seria um exagero dizer que o grupo de mulheres que liderou a idéia de promover o Seminário das Escolas Técnicas do SUS do Estado de São Paulo (SET-SUS) tenha forçado as portas da Associação Paulista de Saúde Publica (APSP) e nos obrigado a fazer este Seminário. Todavia, há que se registrar que elas romperam barreiras e abriram caminhos para chegar até o momento de realização do mesmo, já que não existia tradição estabelecida de se discutir de maneira sistematizada a educação técnica nos Congressos Paulistas de Saúde Pública.

Essas mulheres passaram pela batalha da captação de recursos para viabilizar o Seminário, pelo planejamento e realização da sua divulgação e pela organização da infra-estrutura de transporte e de hotel para acolher os, aproximadamente, 200 participantes que elas mobilizaram nas cidades paulistas onde há centros de formação técnica Araraquara, Assis, Franco da Rocha, Osasco, São Paulo, e que vieram até
São Pedro para participar do Seminário de Escolas Técnicas do SUS.

Da nossa parte, a APSP, em vista do temário do X Congresso Paulista de Saúde Pública, que lembrava a diversidade do campo, teria sido uma grande incoerência deixar de fora a reflexão sobre a formação técnica no SUS, principalmente, se essa abre perspectiva para uma proposta pedagógica mais crítica, ou se propõe a fortalecer capacidades de construção e de re-elaboração do conhecimento pelos sujeitos, estimulando-os à reflexão e à articulação entre ensino, serviço e ação junto com a população.

Quem aceita uma proposta de acolher um evento relacionado com educação técnica compreende a necessária diversidade na formação de profissionais de saúde e o caráter estratégico e político de se buscar convergências interdisciplinares em uma arena permeada por múltiplas tensões.

Nesse sentido, o papel do educador é central, pois não basta cumprir um mero papel de professor, mas desempenhar um engajamento, quase militante, que implique e comprometa sujeitos com a ação transformadora, ao se provocar conflitos cognitivos e desconfortos que possibilitem desconstrução, problematização, sínteses e reflexões que sejam vivas e dinâmicas e com alto poder de mobilização.

Sob essa égide, se reuniram os sete centros de formação do estado de São Paulo para explicitar e compartilhar propostas, projetos e caminhos, para fortalecer, não só a formação técnica no Estado, mas para, também, ecoar sua voz para além das fronteiras paulistas, e reverberar junto aos outros 30 centros distribuídos por todas as regiões brasileiras, que formam a Rede de Escolas Técnicas do SUS (RET-SUS).

Em esse sentido, o material produzido pelo RETSUS paulista deve servir de base para um diálogo nacional, enriquecendo-se com a experiência dos outros Centros Formadores do país, posto a prova no cotidiano da formação técnica paulista, e submetido a múltiplos exercícios de reflexão coletiva como o ocorrido no X Congresso Paulista de Saúde Publica.

Assim, nessa espiral crítica e coletiva, permeada pelos atos de refletir, dialogar e agir, a formação técnica no SUS vai adquirindo cada vez mais uma maior permeabilidade analítica que lhe permitirá entrar por muitas portas abertas (ou não) para se estabelecer como parte integrante de congressos estaduais e nacionais de saúde coletiva. 